\title{
La dignidad humana según el debate Burke us Paine hallado en las obras Reflexiones sobre la revolución en Francia y Derechos del hombre
}

Andrés Eduardo Gómez Alarcón

Universidad Industrial de Santander, Colombia 


\title{
La dignidad humana según el debate Burke us Paine hallado en las obras Reflexiones sobre la revolución en Francia y Derechos del hombre*
}

Resumen: la presente investigación tuvo su origen en la búsqueda de las raíces del concepto actual de dignidad humana. De ahí que el lector pueda ver en este escrito el resultado del análisis sobre dicha noción en uno de los debates más importantes del siglo XVIII, a saber, el que sostuvieron, por un lado, el liberal e historicista Edmund Burke y, por el otro, el liberal e individualista Thomas Paine, el cual tuvo como base las circunstancias que rodearon la Revolución Francesa de 1789. En el curso del texto serán identificadas y confrontadas ambas propuestas, específicamente en lo atinente a la dignidad, tanto la del británico, en el libro Reflexiones sobre la Revolución en Francia de 1790, que está fincada en la defensa de la tradición, la misma que conlleva un gobierno moderado y limitado donde se respetan los derechos que el uso y la costumbre le otorgan al hombre en sociedad; como la del estadounidense, hallada en Derechos del hombre de 1791, para quien la fuente de los derechos y las libertades es la naturaleza propia del hombre fuera de la sociedad, razón por la cual, en ésta solo hay un intercambio de los derechos naturales que en nada pueden afectar el uso y el goce de los mismos.

Palabras clave: dignidad humana, liberalismo, conservadurismo, iusnaturalismo, derecho, valor.

\section{Human dignity according to the debate Burke us Paine found in the works Reflections on the revolution in France and Rights of man}

\begin{abstract}
: the present investigation had his origin in the search of the roots of the current concept of human dignity. Hence the reader could see in this writing the result of the analysis on the above mentioned notion in one of the most important debates of the XVIIIth century, to knowing, which they supported, on the one hand, liberal and historicist Edmund Burke and, for other, liberal and individualistic Thomas Paine, who took as a base the circumstances that surrounded the French Revolution of 1789. In the course of the text there will be identified and confronted both proposals, specifically with regard to the dignity, so much that of the Briton, in the book Reflect on the Revolution in France of 1790, which is established in the defense of the tradition, the same one that bears a moderate and limited government where the rights are respected that the use and the custom they give man in society; as that of the American, found in Rights of the man of 1791, for whom the source of the rights and the freedoms is the proper nature of the man out of the society, reason for which, in this one only there is an exchange of the natural rights that in nothing can affect the use and the enjoyment of the same ones.
\end{abstract}

Keywords: human dignity, liberalism, conservatism, iusnaturalism, right, value.

Fecha de recepción: 2 de septiembre de 2018

Fecha de aceptación: 19 de noviembre de 2018

Forma de citar (APA): Gómez-Alarcón, A. (2019). La dignidad humana según el debate Burke vs Paine hallado en las obras Reflexiones sobre la revolución en Francia y Derechos del hombre. Revista Filosofía UIS, 18(1), doi: http://dx.doi.org/10.18273/revfil.v18n1-2019001

Forma de citar (Harvard): Gómez-Alarcón, A. (2019). La dignidad humana según el debate Burke vs Paine hallado en las obras Reflexiones sobre la revolución en Francia y Derechos del hombre. Revista Filosofía UIS, 18(1), 21-49.

Andrés Eduardo Gómez Alarcón: colombiano. Abogado y filósofo. Profesor, Universidad Industrial de Santander. Especialista en Derecho Administrativo, Universidad Nacional de Colombia.

Correo electrónico: aega1391@gmail.com

ORCID: https://orcid.org/0000-0001-7701-5444

*Artículo de investigación científica. 


\section{La dignidad humana según el debate Burke us Paine hallado en las obras Reflexiones sobre la revolución en Francia y Derechos del hombre}

\section{Introducción}

Desde su incorporación en el Preámbulo y tres artículos de la Declaración Universal de los Derechos Humanos, la dignidad humana ha pasado a ser parte fundamental de este discurso ${ }^{1}$ y ha estado sujeta a amplios debates dentro de dos de las Ilamadas ciencias humanas; a saber, la Filosofía y el Derecho. Precisamente, el debate nació debido a que, como lo señala McCrudden (2008), "Everyone could agree that human dignity was central, but not why or how" (p. 678).

Por este motivo, en la búsqueda de las raíces de aquel concepto, la disciplina jurídica se ha valido de categorías filosóficas de contenido moral para poder llegar así a un acuerdo conceptual, legal y legítimo. Así pues, según gran parte de la doctrina, la obra de Immanuel Kant se muestra como una de las más importantes en lo que se refiere a la inclusión de la dignidad en su propuesta filosófica práctica² .

En la obra que lleva por nombre Fundamentación a la Metafísica de las Costumbres, el filósofo de Königsberg empieza haciendo una diferenciación de las ciencias bajo dos parámetros, a saber, el formal y el material. Dentro de este último ubica a la ética. Asimismo, señala que, la ética está conformada por su parte empírica (antropología práctica) y por su parte racional (moral o leyes según las cuales todo sucede) (Kant, 2007, pp. 1-2).

Siendo así, el pensador alemán desarrolla una posición deontológica de la ética, al situar el apego a la norma moral (al deber ser) como el fundamento del buen actuar del individuo. Igualmente, enuncia la norma por la cual todo

\footnotetext{
${ }^{1}$ El discurso de los derechos humanos fincado en la dignidad ha sido desarrollado por autores como, por ejemplo, Habermas (1989), Herrera (1989), Marina (2000), Moncho (2003), McCrudden (2008).

${ }^{2}$ Válido sea resaltar algunos autores que han desarrollado su reflexión en torno de la dignidad a partir de Kant, como es el caso de Fletcher (1984) en su texto Human Dignity as a Constitutional Value; el mismo Habermas (1989) en el texto que lleva por nombre El concepto de dignidad humana y la utopía realista de los derechos humanos; Der Pfordten (2009) en On the Dignity of Man in Kant; y Waldron (2009) en su libro Dignity, Rank, and Rights-The Tanner Lectures on Human Values, entre otros.
} 
sucede, que puede llamarse buena en absoluto y sin restricción alguna, a saber, el imperativo categórico: "obra solo según una máxima tal que puedas querer al mismo tiempo que se torne ley universal" (37). Punto de partida del cual se desprenden las máximas que pueden llevar al cumplimiento de la ley por el deber.

No obstante, puede afirmarse que aquél no es el único relevante en la ética kantiana, también lo es el llamado imperativo práctico: "obra de tal modo que uses la humanidad, tanto en tu persona como en la persona de cualquier otro, siempre como un fin al mismo tiempo y nunca solamente como un medio" (42).

Y es que, para Kant, la dignidad es un atributo y una imposición moral que obliga tratar a toda persona como un fin en sí mismo:

En el reino de los fines todo tiene o un precio o una dignidad. Aquello que tiene precio puede ser sustituido por algo equivalente, en cambio, lo que se halla por encima de todo precio y, por tanto, no admite nada equivalente, eso tiene una dignidad (Kant, 2007, pp. 47-48).

Lo anterior, precisamente, porque un ser racional es aquel que obedece solamente la ley que se da a sí mismo, que nace de su propia voluntad y no es más que razón práctica (Kant, 2007, p. 27). Así las cosas, para el filósofo de Könisgberg, la dignidad debe estar ligada a la existencia de una voluntad ${ }^{3}$, que solo es atribuible a seres racionales que se valen de su propio conocimiento.

En suma, lo que caracteriza la dignidad en la ética deontológica que establece Kant es la autonomía de la voluntad de todo ser racional, que se vale de su capacidad como autolegislador para obedecer solo la norma dada por sí mismo. De esta definición, según algunos autores, se nutre el discurso de los derechos humanos (Marín, 2007, p. 1).

Sin embargo, para algunos otros, como es el caso de Aguirre, la concepción kantiana de dignidad no se corresponde en todos los casos con la propuesta por el discurso de los derechos humanos, porque en algunas de sus obras se trata de una noción que:

proviene de su filosofía política y legal, pero no se basa en sus propios conceptos fundamentales, sino que se basa en el significado común y general que ostentaba en ese momento el término 'dignidad' (Aguirre, 2011, p. 50).

\footnotetext{
${ }^{3}$ Kant define la voluntad dentro de su obra de la siguiente forma: [... L La voluntad es pensada como una facultad de determinarse uno a sí mismo a obrar conforme a la representación de ciertas leyes. Semejante facultad sólo en los seres racionales puede hallarse. [...] Pero suponiendo que haya algo cuya existencia en sí misma posea un valor absoluto, algo que, como fin en sí mismo, pueda ser fundamento de determinadas leyes, entonces en ello y sólo en ello estaría el fundamento de un posible imperativo categórico, es decir, de la ley práctica (Kant, 2007, p. 41).
} 

sobre la revolución en Francia y Derechos del hombre

Bajo este presupuesto, el primer sentido de dignidad en Kant es legal y político (derivado de un rango o posición social), el cual se aplica por analogía al dominio de la ética, en forma de valor especial y único predicable de los seres humanos como seres racionales.

Aun así, el filósofo alemán seguirá siendo un referente en las discusiones sobre dignidad humana. Empero, esto no es óbice para buscar en la historia del pensamiento otras raíces que puedan sustentar alguno de los significados que este concepto tiene en la actualidad, como, por ejemplo: (i) el derecho que permite tener derechos (Herrera, 1989, pp. 126-127); (ii) el valor básico fundante (Moncho, 2003, p. 189); (iii) el gancho trascendental que permite afirmar que el ser humano tiene un valor intrínseco (Marina et al., 2000, pp. 141-144); o (iv) la fuente moral de todos los derechos fundamentales (Habermas, 2010, p. 9).

Por esa razón, como aporte a la discusión, fue elegido para esta investigación uno de los grandes debates que nació en virtud de la Revolución Francesa y abordó en su seno el tema de los derechos del hombre: se está hablando del debate Burke versus Paine, en el siglo XVIII. Un debate entre dos de los intelectuales más importantes de la época y, quizá, de toda la historia política de Occidente, quienes representaron dos corrientes diferentes del iusnaturalismo liberal dieciochesco.

La metodología usada para la elaboración de este texto fue documental o bibliográfica. Siguiendo el modelo propuesto por el chileno Bascuñán (1971), esta investigación se desarrolló cumpliendo con las siguientes etapas, a saber, primera, la etapa aporética o de planteamiento ${ }^{4}$. Segunda, la etapa heurística o de erudición ${ }^{5}$, que fue abordada con base en las fuentes primarias y secundarias sometidas a tres filtros, hasta llegar a la diagnosis y registrar en fichas de resumen el contenido de la bibliografía escogida. La tercera, etapa de análisis o construcción ${ }^{6}$, se llevó a cabo, luego de la recolección de datos y el filtro correspondiente, dejando así la bibliografía base para la investigación. Por último, la etapa formal o de comunicación ${ }^{7}$, dentro de la cual se estructuró el artículo y la forma de escritura, tal cual se pasará a mentar.

\footnotetext{
${ }^{4}$ Se incluyen aquí la selección del tema y sistematización del problema, los objetivos generales y específicos, los supuestos o hipótesis, la metodología (método técnicas e instrumentos), el cronograma de actividades o planificación (Bascuñán, 1971).

${ }^{5}$ Consiste en: la identificación y localización de las fuentes del conocimiento jurídico, la reconstrucción o selección crítica, la fijación y clasificación provisoria (Bascuñán, 1971).

${ }^{6}$ Corresponde al: procesamiento de los datos (clasificación y ordenación definitiva), análisis de los datos (a partir de una teoría general y los supuestos o hipótesis), interpretación de los datos (ampliación de las teorías e hipótesis), generalización o tesis de demostración, síntesis (conclusiones, proposiciones, sugerencias o recomendaciones) (Bascuñán, 1971).

Concluye con la estructuración de la exposición (introducción, cuerpo o desarrollo, conclusiones y fuentes), expresión monográfica (ajustándose a las normas de elaboración y presentación de trabajos de investigación) (Bascuñán, 1971).
} 
Antes de empezar con el contenido del escrito, válido sea aclarar desde ahora, para evitar caer en anacronismos, que, si bien en el siglo XVIII la noción de dignidad humana carecía de significante, no por esto lo hacía también de significado. Es más, con este trabajo se pretende posicionar este debate como una de las bases más sólidas del concepto de dignidad humana, manejado actualmente por el discurso de los derechos humanos, por cuanto presenta dos posturas que nutren de contenido a la noción, tanto en su matiz teórica como práctica, haciendo de su tratamiento algo impajaritable para cualquiera que desee hablar de ese valor social e institucional que otorga un estatus o aquel derecho que es natural al hombre por su mera condición.

El texto se dividirá en cuatro secciones. En primer momento, la identificación del concepto de dignidad dentro del análisis burkeano a la Revolución Francesa; seguidamente, será esquematizada la respuesta racionalista de Thomas Paine a la crítica tradicionalista de Burke; luego, como paso previo a las conclusiones del texto, serán analizadas y confrontadas las teorías puestas sobre la mesa, enmarcadas dentro del tronco iusnaturalista liberal de la época, pero en distintas ramas; esto es, historicismo e individualismo; y, por último, serán expuestas las conclusiones que esta investigación pueda recoger en su desarrollo.

\section{La dignidad como valor social e institucional en Edmund Burke}

Para empezar este apartado es menester enmarcar el pensamiento de Edmund Burke en una de las ideologías políticas fruto de la modernidad (Espejel, 2015, p. 119); es decir, el liberalismo y el conservadurismo. Sin embargo, en la doctrina no se evidencia una postura pacífica en relación con el lugar que ocupa la propuesta política del irlandés en esa disyuntiva ideológica, más aun luego de la publicación de la obra Reflexiones sobre la Revolución en Francia en 1790.

Por un lado, están aquellos que lo encuentran íntimamente ligado a tendencias conservadoras y cuestionan su rechazo a la universalidad de los derechos del hombre, como es el caso de Berlin, según el cual:

[...] el famoso ataque de Burke contra los principios revolucionarios franceses estaba fundado sobre el mismísimo llamado a los miles de hilos que atan a los seres humanos dentro de un todo históricamente sagrado [...] Este énfasis, durante la última mitad del siglo XVIII, sobre factores no racionales, conectados o no con relaciones religiosas específicas, que hace hincapié en el valor de lo individual, lo peculiar, lo impalpable, y hace referencia a las antiguas raíces históricas y costumbres inmemoriales, a la sabiduría de los sencillos y macizos campesinos no corrompidos por las complicaciones de sutiles 'razonadores' tienen implicaciones fuertemente conservadoras, $y$, ciertamente, reaccionarias (1983, pp. 72-73). 

sobre la revolución en Francia y Derechos del hombre

Y, especialmente, Peces-Barba, para quien no es de extrañar que Burke sea llamado "padre del conservadurismo", ya que, en su opinión: (i) "el conservadurismo surge sólo como necesaria respuesta a las teorías que, a partir del siglo XVIII, se desprendieron de la visión antropológica tradicional para reivindicar para el hombre la posibilidad no solo de mejorar sus propios conocimientos y su propio dominio sobre la naturaleza, sino a través de los unos y el otro, lograr una comprensión cada vez mayor y, por tanto, la felicidad" (Peces-Barba, 2001, pp. 378-379); y (ii) "[...] porque las funciones y límites que E. Burke asigna a la política tiene mucho que ver con lo que hoy día caracteriza al pensamiento conservador, liberal-conservador y neoconservador" (378-379).

Por otro lado, como lo advierte Botero (2008), en la Inglaterra del siglo XVIII, antes de la aparición de las obras de Burke, los conservadores eran los defensores del absolutismo monárquico. Los liberales, por su parte, fundaban el derecho en el Bill of Rights o Declaración de Derechos de 1689, por ende, lo consideraban un conjunto primordialmente consuetudinario que incluía libertades negativas, bajo el binomio Liberty and Property (Botero, 2008, p. 598). Por ende, siendo que el irlandés apoyaba el derecho fundado en la tradición, su pensamiento no podía estar alejado de la ideología política liberal.

De ahí que existan quienes, a diferencia de Berlin y Peces-Barba, resalten la gran influencia liberal en el pensamiento de Burke, sobre todo con el uso de categorías puras del liberalismo como la utilidad, la igualdad ${ }^{8}$ y la propiedad privada, las cuales se desarrollan en el marco de una visión organicista del mundo.

Para Suñé, Burke es un tradicionalista liberal o un liberal organicista (1987, p. 321). Es que, aun cuando se habla de organicismo político, es decir, aquella teoría conservadora que ubica al hombre concreto como un individuo en la sociedad que desempeña diversos roles (Espejel, 2015, p. 132); para el español, la propuesta burkeana ofrece otros matices:

Insisto en que el organicismo de Burke es de cuño liberal, ya que pese a ser organicista en la consideración del hombre concreto; es decir, el hombre social («art is man nature», dice Burke), éste piensa también que el origen de la sociedad se basa en un contrato entre individuos libres que renuncian

\footnotetext{
${ }^{8}$ Es importante aclarar que para Burke, la igualdad derivada de nuestra naturaleza común no justifica la igualdad política. Esto, como consecuencia de la realidad del derecho a propiedad privada, el cual debe ser respetado y hace que la representación política sea desigual. En palabras del irlandés: "Los ricos no pueden pensar que esto suponga un apoyo a su dignidad o una garantía de seguridad a su fortuna; porque la masa aristocrática se genera a partir de principios puramente democráticos, y la preferencia que se concede a ésta en la representación general no tiene referencia ni conexión alguna con las personas cuyas propiedades se ha establecido la superioridad de la masa" (Burke, 2013. p. 262).
} 
a parte de sus derechos naturales para que sea posible la existencia de la sociedad. Como vemos, pues, en último término la génesis de la sociedad está en el individuo; y éste, al entrar en ella no renuncia a su libertad, sino que hace que la libertad absoluta, que en el estado de naturaleza era sinónima de la fuerza, se convierta, en el marco del Derecho, en algo «viril, moral y ordenado», que, esto si, merece el nombre de libertad (Suñé, 1987, p. 303).

En el mismo sentido, García (2016) califica de liberal la obra del irlandés y afirma que tildarlo de conservador es producto de una conjunción de factores históricos ajenos al fundamento filosófico-político de su acción, como, por ejemplo, la ruptura con los Whigs ${ }^{9}$ luego de las Reflexiones sobre la Revolución en Francia (en adelante Reflexiones) y el uso que de sus obras hicieron los conservadores estadounidenses en la Guerra Fría (1947-1991) (p. 12).

La labor realizada hasta el momento tiene como fin ilustrar al lector sobre la importancia del debate que se muestra en este artículo, toda vez que no se trata de una disputa entre una postura conservadora y otra liberal totalmente opuestas, representadas por un británico y un estadounidense respectivamente, en el lejano siglo XVIII. Por el contrario, como afirma Botero (2008), se trata de un choque entre dos posturas liberales que comparten algunas bases pero que se distancian en otras, representadas por dos autores con raíces británicas, sobre un hecho que marcó la historia del pensamiento político europeo, a saber, la Revolución Francesa (p. 599).

Teniendo claridad en este aspecto, es tiempo de seguir el curso del texto acudiendo a una de las obras que componen este debate: Reflexiones. Válido sea advertir que, más que una referencia directa a la dignidad humana, Burke desarrolla la noción de dignidad como un valor social e institucional en el contexto público de un Estado, con lo cual, trasciende al individuo como tal.

Así pues, la primera alusión significativa que el pensador irlandés hace con respecto al carácter de la dignidad denota el respeto a la tradición y está intrínsecamente unida con la noción de libertad como algo heredado de los antepasados. En palabras del autor:

Esta idea de un linaje liberal nos inspira con un sentido de congénita dignidad habitual que nos mantiene a salvo de caer en esa insolencia inmadura que casi inevitablemente suele afectar y perjudicar a quienes por primera vez adquieren alguna distinción. De este modo, nuestra libertad se convierte en una libertad noble y adquiere un aspecto imponente y majestuoso; tiene

\footnotetext{
${ }^{9}$ Era el tradicional partido liberal británico en el cual militó Edmund Burke, en virtud del apoyo que le proporcionaba el marqués de Rockingham. Luego de la caída del gobierno del marqués en 1776, Burke lo acompañó por dieciséis años más en las filas moderadas del partido. La ruptura se dio con ocasión de la publicación de la obra Reflexiones sobre la Revolución en Francia (Burke, 2013, p. 9).
} 

sobre la revolución en Francia y Derechos del hombre

pedigrí y una ilustre genealogía; tiene sus blasones y sus escudos de armas; tiene una galería de retratos, inscripciones monumentales, documentos testimoniales, pruebas y títulos (Burke, 2013, p. 70).

Esta crítica se presenta a los que por primera vez obtienen una distinción, a los radicales que afirmaron su libertad a través de tres derechos fundamentales: (i) el derecho a elegir a sus gobernantes; (ii) el derecho a destituirlos por mala conducta; y, sobre todo, (iii) el derecho del pueblo a establecer un gobierno por ellos mismos (Burke, 2013, p. 45).

Y es que el estadista whig ${ }^{10}$ no está de acuerdo con el concepto de libertad absoluta manejado por los revolucionarios franceses, lo tilda de mera abstracción metafísica, al igual que todo el conglomerado que conforma el discurso de los derechos del hombre (Burke, 2013, p. 33). Es más, afirma de manera concreta que esos pretendidos derechos de que hablan los racionalistas radicales son excesivos; y en la misma medida en que son metafísicamente correctos, son moral y políticamente falsos (Burke, 2013, p. 107). Frente a este tema, tal cual indica Bariffi:

[...]es claro que para Burke los verdaderos derechos no pueden ser naturales puesto que surgen históricamente de la relación entre gobierno y sociedad civil, donde el primero concebido como un sujeto exterior a los súbditos, y no sujeto a la voluntad y pasiones generales, sirve como instrumento de ingenio humano para la satisfacción de las necesidades humanas (2003, p. 274).

Retomando, la libertad absoluta solo pudo existir en el estado de naturaleza previo a la conformación de la sociedad civil (Burke, 2013, p. 35). Siendo así, la libertad no puede ser entendida sin la prudencia y las circunstancias, que son el matiz y la concreción de todo principio político. En consecuencia, más allá de ser una construcción abstracta, la libertad debe estar acompañada de adjetivos como "viril", "moral" y "regulada" para poder llegar a ser una libertad civil (Burke, 2013, p. 33).

Para García (2016), la libertad liberal del estadista whig es la "eleutheria": (i) que florece bajo el Imperio de la ley; (ii) que exalta la justicia y maximiza la dignidad de la persona, y que, a su vez, (iii) crea un orden social perfectible con base en el buen gobierno, en la prudencia y en el conocimiento que es la tradición (p. 26).

Es así como, de manera categórica, el irlandés responde a los críticos de Inglaterra: "Vosotros si lo hubierais deseado, podríais haberos beneficiado

\footnotetext{
10 Según Escolano (2012), rigurosidad con la que el irlandés defiende su posición filosófica, política y jurídica favorable a la tradición, el derecho evidenciado en la historia y el establisment, además de su experiencia en la Cámara de los Comunes y en el partido Whig, son razones suficientes para considerarlo un estadista (pp. 52-54).
} 
de nuestro ejemplo y haber dado a vuestra recobrada libertad la dignidad correspondiente. Vuestros privilegios, aunque interrumpidos, no habían sido totalmente olvidados [...] En vuestras viejas instituciones poseíais una variedad de partes que se correspondían con las varias características de que vuestra comunidad estaba afortunadamente compuesta" (Burke, 2013, pp. 70-71).

Ahora, otra muestra de la naturaleza que posee la dignidad en Reflexiones se exhibe en el cuestionamiento que Burke hace a los "curas de pueblo", que apoyaron los afanes insurreccionales de los radicales franceses, quienes buscaron acabar con el establishment. Es así como señala:

Los hombres turbulentos de las clases altas, generalmente desprecian a los de su propia clase en proporción a su grado de vanidad y arrogancia personales. Uno de los primeros síntomas que revelan una ambición egoísta y perniciosa es la libertina desconsideración para con una dignidad que se comparte con otros. Ser solidarios con los de nuestra subdivisión, amar a ese pequeño escuadrón al que pertenecemos en la sociedad, es el primer principio (algo así como el germen) de los afectos públicos. Es el primer eslabón por la que procedemos a amar a nuestro país y a la humanidad (Burke, 2013, p. 86).

Es notorio su apego a las costumbres y al hábito, en otras palabras, a la tradición que se ve representada en las instituciones que cumplen su cometido en la sociedad civil. En párrafos posteriores, continúa su crítica al supremo individualismo que reinó en la Francia revolucionaria al proclamar:

Cuando hombres de posición sacrifican toda idea de dignidad a una ambición sin objeto definido, y ponen los medios más despreciables para alcanzar fines igualmente mezquinos, el entramado entero se hace vulgar y plebeyo ¿No ocurre algo de esto en Francia en estos momentos? ¿No se ha producido algo innoble y vergonzoso, una suerte de bajeza en todas las medidas políticas que hoy prevalecen, una tendencia, en todo lo que se hace, a rebajar a todos los individuos y a disminuir la dignidad del Estado? Otras revoluciones han sido llevadas a cabo por personas que, aunque intentaron o lograron efectuar cambios en el Estado, santificaron su ambición elevando la dignidad del pueblo cuya paz habían perturbado. Tuvieron una visión de largo alcance. Su objetivo era gobernar el país, no destruirlo'11 (Burke, 2013, p. 88).

\footnotetext{
11 Ahora, si bien el objeto de la investigación dista mucho de un estudio filológico, sea útil aclarar al lector que en la traducción de Carlos Mellizo, dos palabras del idioma original del autor irlandés, a saber, "state" y "commonwealth", son usadas para representar el mismo término: "Estado". Tal es así que en la versión inglesa de esta cita indica: "When men of rank sacrifice all ideas of dignity to an ambition without a distinct object and work with low instruments and for low ends, the whole composition becomes low and base. Does not something like this now appear in France? Does it not produce something ignoble and inglorious - a kind of meanness in all the prevalent policy, a tendency in all that is done to lower along with individuals all the dignity and importance of the state? Other revolutions have been conducted by persons who, whilst they attempted or affected changes
} 

sobre la revolución en Francia y Derechos del hombre

Se reitera, pues, la idea de una dignidad ligada al oficio o posición social (estamento) más que al hombre en sí. Igualmente, se muestra la mutabilidad del concepto, siendo que responde a lo que la organización política requiere (dignidad del Estado), haciendo palpable su inclusión dentro de la visión organicista como un valor social e institucional en el contexto público.

Siguiendo a Suñé, el nacido en Dublín considera a la organización política como inherente a la sociedad. De ahí, lo fundamental del contrato social, porque hace parte del orden querido por Dios, de cuya voluntad y sanción deriva su fuerza de obligar. En consecuencia, el contrato social que constituye al Estado no puede disolverse por razones netamente políticas sin que su efecto disuelva también a la sociedad (Suñé, 1987, p. 307).

Esa unión entre la religión, representada en la Iglesia, y el Estado, que se sacraliza por medio del pacto social es el paliativo de la desigualdad originada por la propiedad (Burke, 2013, pp. 92-93). En otras palabras, para Burke significa: "el adorno público. Es el público consuelo. Es el alimento de la esperanza pública. Hasta el hombre más humilde encuentra en ellos su propia importancia y dignidad, aunque la riqueza y arrogancia de individuos particulares quieran en todo momento hacer que el hombre de modesta condición y escasa fortuna sea consciente de su inferioridad y traten de degradarlo y humillarlo" (158).

Es claro, pues, el talante socio-político de la dignidad en cuanto a que el engranaje del Estado funciona si cada uno respeta y cumple las labores que de su estamento, posición u oficio se derivan. Asimismo, tiene aparejado un aspecto legal, ya que a través del pacto social se establecen los derechos además de los deberes, heredados de los antepasados y reflejados en la historia, de los que goza el pueblo gracias al orden natural de las cosas.

De la mano con lo dicho hasta ahora, para el estadista whig, un tópico de gran importancia en el Estado es la renta pública, la cual tiene, a su vez, estrecha relación con la noción de dignidad de cada rango u honor. Según el autor:

La dignidad de cada ocupación depende enteramente de la cantidad y calidad de virtud que pueda ejercerse sobre ella. Como todas las grandes cualidades de espíritu que actúan sobre la cosa pública y que no son únicamente receptivas y pasivas requieren fuerza para manifestarse (casi iba a decir que para garantizar su misma existencia), la renta publica, que es resorte de todo poder, llega a ser en su administración la esfera de toda virtud activa. La virtud publica, al ser de naturaleza magnifica y espléndida, y al haber sido instituida para realizar grandes cosas y ocuparse de grandes intereses, requiere que se le dé abundante amplitud y alcance; y no puede

in the commonwealth, sanctified their ambition by advancing the dignity of the people whose peace they troubled. They had long views. They aimed at the rule, not at the destruction, of their country" (Negrilla propia) (Burke, p. 40). 
extenderse y crecer cuando se halla confinada y constreñida por una serie de circunstancias mezquinas y sórdidas. Es solo mediante la renta pública cómo el cuerpo político puede actuar de acuerdo con su auténtico genio y carácter (Burke, 2013, p. 328).

Tal como se evidencia, no solo hay una estrecha relación entre la renta pública y la dignidad, sino entre éstas y las virtudes, especialmente con la primera de todas, a saber, la prudencia (Burke, 2013, p. 107). Una prudencia en términos aristotélicos y tomistas, es decir, sabiduría práctica que suplanta a la ciencia teórica y ayuda a discernir el derecho natural y su adecuación a las circunstancias (García, 2016, p. 122).

Y es que, únicamente con la práctica de la virtud se puede prevenir que los vicios se impongan a la razón, por ende, la prudencia, como virtud máxima, toma corporeidad en la Constitución británica, que se instituye en la suma de costumbre y tradición (Burke, 2013, p. 412).

A partir de la prudencia, no solo se puede entender la dignidad en clave sociopolítica y legal, en otras palabras, las dignidades cívicas; sino también se puede llegar a tener un acercamiento de la dignidad como atributo del ser humano en cuanto tal, en lo que respecta a Reflexiones, claro está. Y es en el trato con la realeza donde se encuentra tal referencia, ya que mientras el soberano respete el pacto originario de soberanía, el pueblo no tiene motivo fundado para aspirar a la elección de uno nuevo (Suñé, 1987, p. 321).

Empero, en el caso contrario, cuando el soberano incumpla el pacto, el estadista whig aconseja: "Castigar a los reyes tiranos es un noble y estremecedor acto de justicia, y con verdad se ha dicho que sirve de consuelo al espíritu humano. Pero si yo tuviera que castigar a un rey malvado, vengaría su crimen sin perder de vista la dignidad de la persona. La justicia es grave y decorosa; y cuando castiga parece estar sometiéndose a una necesidad, más que estar eligiendo un modo de actuar" (Burke, 2013, p. 137).

Ahora bien, no piense el lector que se está faltando a la objetividad y extralimitando el texto al notar alguna relación entre la dignidad humana y el extracto traído a colación, toda vez que parece ser una reafirmación del sentido socio-político y legal que tiene la dignidad en esta obra, porque no se trata de cualquier persona (hombre), sino de la persona del rey o soberano; por el contrario, lejos de caer en esos errores, es acertada esta elucubración.

Pese a esto, es inevitable ligar la propuesta de Burke con el pensamiento medieval, máxime cuando su tradicionalismo liberal lo impide, es por esto que 

sobre la revolución en Francia y Derechos del hombre

la cita anterior habilita a pensar que el autor de las Reflexiones llega a concebir que el hombre al ser hecho a la imagen de Dios se le han otorgado dones que lo distinguen de otros seres. Así pues, la dignidad sirve como puente entre el pensamiento romano clásico y la doctrina de la Iglesia, la cual destaca el don de la razón. De esta forma, usar la razón está estrechamente relacionado con la idea de la dignidad.

Esto se puede evidenciar en una de las obras más influyentes del humanismo medieval, a saber, Discurso sobre la dignidad del hombre, publicada en 1486, donde Pico della Mirandola argumentó que la raíz de la dignidad del hombre está en la capacidad de elegir ser lo que quiere ser y que esto es un regalo de Dios. Se dice en esa hermosa oración: iOh suma libertad de Dios padre, oh suma y admirable suerte del hombre al cual le ha sido concedido obtener lo que desee, ser lo que quiera! (Pico della Mirandola, 2010, p. 5).

En definitiva, aun cuando se pueda distinguir algún rastro de una noción de dignidad natural al hombre, más que por su posición, rango u honor en la sociedad, por el simple hecho de ser una criatura dotada de razón para elegir ser lo que quiera, siendo, de esta forma, más sencillo ligarlo con la idea contemporánea de dignidad humana; en la obra puesta bajo análisis, no se encuentra más que una significación socio-político y legal del concepto de dignidad, con lo cual, a lo sumo, puede hablarse de un valor dentro de la sociedad y no fuera de ella.

Una vez identificado el concepto de dignidad, dentro de una de las obras que componen este debate, es preciso seguir adelante con el curso de la investigación y realizar el mismo ejercicio hecho con Reflexiones para dilucidar el sentido que se le otorga a esta noción en la obra de Thomas Paine.

\section{La dignidad como derecho en Thomas Paine}

Dando continuidad a este escrito, sea útil señalar que el pensamiento de Thomas Paine ha sido pacíficamente asociado por la doctrina a tendencias liberales racionalistas o individualistas radicales. Así pues, para algunos autores, como es el caso de Pisarello, en el nacido en Thetford confluyen los elementos más ricos de las posturas liberales, democráticas y socialistas, al punto de afirmar que, sin lugar a dudas, fue un revolucionario (Pisarello, 2000, p. 21). En igual sentido, García indica que se "trata del primer escritor político moderno que se expresó en la lengua del ciudadano corriente, dándole los argumentos necesarios para participar en el debate político de la época y defender sus derechos dentro de un sistema democrático" (2017, p. 11). 
Habiendo zanjado este tema, se hace necesario adentrarse en la obra del pensador estadounidense, la misma que tituló Derechos del Hombre en $1791^{12}$ (en adelante Derechos), con el fin de indagar acerca de su concepción de la dignidad humana o, en su defecto, como sucedió con el estadista whig, lograr determinar el sentido que la noción de dignidad juega en su propuesta política.

Siendo así, el uso más importante que del concepto de dignidad puede ofrecer Derechos nace del cuestionamiento que hace Paine a la posición de Burke, en relación con el discurso que está detrás de la Declaración de los Derechos del Hombre y el Ciudadano. Por esa razón, es indispensable ahondar en el requerimiento que se le al inglés, de la siguiente forma:

¿Quiere el Sr. Burke negar que el hombre tiene derecho alguno? Si es así, entonces debe significar que no existen esos que se llaman derechos en parte alguna, y que él mismo no tiene ninguno; pues ¿quién hay en el mundo que sea más que un hombre? Pero si el Sr. Burke se propone reconocer que el hombre tiene derechos, entonces la pregunta es: ¿Cuáles son esos derechos y cómo los adquirió el hombre en un principio? (Paine, 2008, p. 93).

Para Paine, es difícil de comprender dónde ha de residir el Derecho sino es en el hombre, de ahí que no entienda la corriente más clásica del iusnaturalismo. Y es que, la doctrina de los derechos del hombre parte del "yo racional" en el que se arraigan la moral y el Derecho, mientras que la doctrina clásica del derecho natural comporta la creencia de que la ley humana, propia de un cuerpo social, forma parte de un orden cósmico establecido por la ley de Dios y reflejado en la ley natural, por medio de la historia (Suñé, 1987, p. 323).

Es más, el nacido en Thetford critica a los autores que, para atacar el discurso racionalista, van a la antigüedad de manera parcializada, sin profundidad, los que solo buscan el choque de dos autoridades históricas sin llegar al origen divino del mismo hombre, solo interponiendo barreras entre el Creador y su creación. En palabras del autor:

El error de quienes razonan conforme a precedentes extraídos de la antigüedad, por lo que respecta a los derechos del hombre, es que no llegan lo bastante lejos en la antigüedad. No recorren todo el camino. [...] pero si seguimos adelante por fin llegamos a la verdad; llegaremos al momento en

\footnotetext{
${ }^{12}$ La obra Derechos del hombre o Rights of man está dividida en dos partes, la primera de ellas fue publicada en 1791 y será la base para este capítulo, toda vez que, constituye la respuesta directa del pensador estadounidense a los postulados de Edmund Burke en la obra Reflexiones sobre la revolución en Francia de 1790. La segunda parte, publicada en 1792, según algunos autores, corresponde a una defensa más organizada de su posición como liberal radical, además de ser una respuesta al texto de Edmund Burke Apelación de los Nuevos a los Viejos whigs o Appeal from the New to the Old whigs, publicado en 1791, razón por la cual no será trabajada en esta investigación (García, 2017, p. 227).
} 
que el hombre salió de la mano de su Creador ¿Qué era entonces? Hombre. Su excelso y único título era el de hombre, y no cabe darle otro más excelso (Paine, 2008, p. 94).

A partir de ese origen divino del hombre, la igualdad y la unidad de los mismos en una sola categoría, es desde donde el estadounidense introduce otra crítica fundamental al pensamiento burkeano, esta vez dirigida al establishment, especialmente, a los derechos de nacimiento y familia en favor de la nobleza o aristocracia, que tanto defiende el estadista whig (Paine, 2008, pp. 95-96).

Posteriormente, con el objeto de demostrar que los derechos naturales son la base de los derechos civiles, además que el hombre únicamente ingresó a la sociedad para que aquéllos estuvieran mejor protegidos sin que este hecho hubiera representado una renuncia expresa a seguir gozando de sus beneficios, pasa a definir ambas categorías:

Los derechos naturales son los que pertenecen al hombre por el mero hecho de existir. De este género son todos los derechos intelectuales, o derechos de la mente, así como todos los derechos de actuar como individuo para su bienestar y felicidad propios, siempre que no vayan en contra de los derechos naturales de otros. Los derechos civiles son los que pertenecen al hombre por su condición de miembro de la sociedad. Cada derecho civil tiene su base en algún derecho natural preexistente en el individuo, pero para el goce del cual sus facultades individuales no son en todos los casos, suficientes. De este género son todos los relacionados con la seguridad y la protección (Paine, 2008, pp. 97-98).

Así pues, una vez el hombre entra en la sociedad civil algunos derechos, perfectos en el individuo, no pueden conservarse porque su facultad de ejecución es deficiente, por lo cual debe ser intercambiado en la sociedad: el derecho de juzgar en su propia causa. Empero, muchos otros de sus derechos naturales pueden conservarse, porque esa facultad de ejecución, perfecta en el individuo, también lo es en el derecho en sí, como es el caso de la igualdad, la libertad y la religión ${ }^{13}$. Como lo destaca Pisarello, en el fondo se trata de una pretensión universalista de los derechos (2000, p. 19).

\footnotetext{
${ }^{3}$ Es llamativo, máxime si se tiene en cuenta que propone una suerte de parámetros para entender su pensamiento sobre los derechos a partir de tres conclusiones: "Primera, todo derecho civil procede de un derecho natural; o, dicho en otros términos, es un derecho natural intercambiado. Segunda, que el poder civil, propiamente considerado como tal, está formado por la suma de esa clase de los derechos naturales del hombre, que se convierte en deficiente en el individuo por lo que hace a los poderes y no responde a sus propósitos, pero cuando se reúne en un foco pasa a ser competente para los fines de todos. Tercera, que los poderes producidos por la suma de los derechos naturales, imperfectos en poder del individuo, no se pueden aplicar para invadir los derechos naturales que conserva el individuo, y en los cuales la capacidad de ejecución es tan perfecta como el derecho en sí mismo" (Paine, 2008, pp. 98-99).
} 
Ahora bien, en torno al tema de la religión, si bien Paine lo incluye dentro de uno de los derechos naturales del hombre (Paine, 2008, p. 98), queriendo quizá ligarlo a la libertad de conciencia; es contundente al rechazar cualquier tipo de vínculo entre la Iglesia y el Estado, porque cuando las religiones, amables y benignas por naturaleza, se unen con el Estado, pierden conexión con principios morales y se genera la intolerancia (Suñé, 1987, p. 325).

En consecuencia, ante la defensa que Burke hace de la unión entre Iglesia y Estado, dice: "Al aparearse la Iglesia con el Estado lo que engendra es una especie de mula, capaz solo de destruir, y no de procrear, Ilamada la Iglesia oficial conforme a la Ley. Es, desde el momento mismo de nacer, un ser extraño a su propia madre, que lo engendra, y a la que con el tiempo ataca a coces y destruye" (Paine, 2008, p. 122).

Luego de analizar el origen del hombre y sus derechos naturales, sin perder la intención de responder a las diatribas burkeanas, el autor plantea una clasificación de los gobiernos en función de la fuente en la que se fundan, concluyendo que son tres tipos de gobierno. En primer lugar, los gobiernos originados por la superstición donde los sacerdotes, consultores de oráculos, decían mantener una estrecha relación con la Deidad y, en virtud de esto, manipular la ley a su antojo (Paine, 2008, p. 99).

En segundo momento, se encuentran los gobiernos originados por la fuerza, en los que el conquistador era soberano y la espada su cetro, los cuales al ver que aquélla se desvanecía, le sumaron el fraude, estableciendo con esto un ídolo llamado derecho divino, que con el devenir de la historia se transformó en la Iglesia y el Estado (100). Es este tipo de gobierno, según Paine, el que imperaba en la Inglaterra del siglo XVIII.

Ya en un tercer estadio, está el gobierno que surge de la sociedad y a diferencia de los anteriores, que se dan sobre ésta, se funda en el interés común y los derechos del hombre. Este gobierno de la razón nace en virtud de un contrato social en el que los individuos, haciendo uso de su derecho personal y soberano, acordaron producir un gobierno. Entenderlo de otra manera llevaría a poner el efecto encima de la causa (100-101).

Para Paine, es irracional pensar que el contrato social se dio entre quienes gobernaban y los gobernados, porque antes de la sociedad estuvo el hombre que quiso, por su propia voluntad, conformar una sociedad en la que se conservarán mejor sus derechos naturales; no fue una necesidad derivada de la existencia de pasiones negativas, aunadas a la razón, que necesitaban ser controladas como propone el estadista whig (Suñé, 1987, p. 303). Ahora, en el gobierno racional, ese acto del pueblo es denominado constitución, definida así: 
La constitución no es algo que solo exista de nombre sino, de hecho. No tiene una existencia ideal, sino real; $y$ dondequiera que no se pueda exhibir en forma visible, no existe. Una constitución es algo que antecede a un gobierno, y un gobierno no es más que la criatura de una constitución. La constitución de un país no es el acto de su gobierno, sino del pueblo que constituye su gobierno. Es el cuerpo de elementos al que cabe remitirse y citar artículo por artículo, y que contiene los principales en los que se ha de establecer un gobierno, la forma en que organizará éste, los poderes que tendrá, la forma de las elecciones, la duración del parlamento o cualquier otro nombre por el que se designe a un organismo de ese género, los poderes de que dispondrá la parte ejecutiva del gobierno, y, en fin, todo lo relacionado con la organización completa de un gobierno civil, y los principios en los que se basará y por los que se regirá (Paine, 2008, pp. 101-102).

Por lo tanto, primero, es necesaria una constitución escrita donde se recojan los derechos y las libertades, además de estar abierta a futuras modificaciones; segundo, en ella debe estar plasmada la defensa de la forma democrática y republicana por sobre los privilegios y las garantías hereditarias, con prevalencia del Parlamento (Pisarello, 2000, pp. 10-11).

Como lo indica García (2017), el ataque de Paine a la tradición se explica, inicialmente, por la capacidad de cambio del ser humano; además, por la negación a que el pasado parcializado condicione necesariamente el futuro; y, por último, en razón a la defensa al gobierno de la razón (pp. 216-218).

En este punto, ya esbozados los presupuestos más importantes sobre los que se funda el discurso de los derechos del hombre en Thomas Paine, se preguntará el lector: ¿cuál es la noción de dignidad que se plantea en ese discurso? y iexiste alguna relación entre esa noción y la dignidad humana? Ante lo cual, se hace indispensable traer a colación el siguiente extracto de la obra donde el autor, discutiendo al gobierno de los conquistadores, señala:

Cuando contemplo la dignidad natural del hombre, cuando me penetro (pues la Naturaleza no ha tenido la suficiente bondad para conmigo de embotarme los sentidos) del honor y la alegría de su carácter, me irrita la tentativa de gobernar a la humanidad por la fuerza y el fraude, como si todos fuéramos bellacos e idiotas, y apenas si puedo evitar la indignación ante la forma en que algunos se dejan someter (Paine, 2008, p. 100).

En consecuencia, la respuesta al segundo interrogante planteado es afirmativa. Puede establecerse una clara aproximación a la noción de dignidad de la humanidad, toda vez que al estar íntimamente atada la dignidad con la naturaleza propia del hombre, no está sujeta a condicionantes sociales que puedan llegar a afectarla. 
Es más, y en respuesta al primer interrogante, en Paine, la dignidad ostenta la calidad de derecho natural. Existen dos razones para justificar esta afirmación: en un primer momento, la definición misma de derecho natural como aquél que le pertenece al hombre por el solo hecho de existir, dentro de los que se hallan los derechos de la mente o intelectuales; y en uno segundo, el origen divino del hombre, en virtud del cual se plantea la libertad y sobretodo la igualdad entre todos los hombres como creación de Dios.

Ahora bien, no solo como derecho es usado el concepto de dignidad en la obra del racionalista, también es usado como carácter o singularidad en varias oportunidades dentro del texto, como cuando se refiere a la relación entre la Asamblea Nacional de Francia y el rey francés en comparación con lo que sucedía en Inglaterra. Señala Paine:

El presidente de la Asamblea Nacional no pide al rey que conceda a la Asamblea libertad de palabra, como ocurre en la Cámara de los Comunes inglesa. La dignidad constitucional de la Asamblea Nacional no puede rebajarse. La palabra es, en primer lugar uno de los derechos naturales del hombre que siempre se ha conservado, y con respecto a la asamblea nacional, su uso es su deber, y la nación es su autoridad. Sus miembros los elige el mayor grupo de hombres que el mundo haya visto jamás ejercer el derecho de elección [...] Como tienen conciencia de la dignidad que corresponde a su carácter, la defienden (2008, p. 126).

En este caso, es claro que para el estadounidense el pueblo, representado por la Asamblea Nacional, prevalece por sobre cualquier soberano en virtud de la facultad legislativa otorgada por la constitución. De ahí, que no exista sumisión en el gobierno de la razón, porque "es cabalmente un término de vasallaje, repugnante a la dignidad de la libertad, y eco del lenguaje utilizado en la conquista" (Paine, 2008, p. 127).

Y es que, para Paine, la monarquía no permitía que el pueblo fuera consciente de su dignidad, es por esto que, resumiendo la historia del Antiguo Régimen, previo a la toma de la Bastilla refiere:

El despotismo de Luis XIV unido a la alegría de su Corte y a la llamativa ostentación de su carácter, había humillado tanto, y al mismo tiempo fascinado tanto, la mente de Francia, que el pueblo parecía haber perdido todo sentido de su propia dignidad en la contemplación de la de su gran monarca, y todo el reinado de Luis $\mathrm{XV}$, notable solo por su debilidad y afeminamiento, no introdujo más modificación que la de infundir una especie de letargo en la nación, del cual ésta no parecía estar dispuesta a despertar (Paine, 2008, p. 130).

Igualmente, la nobleza también representaba ese despotismo de los gobiernos de la conquista que debía ser superado por la era de la razón. La Revolución 

sobre la revolución en Francia y Derechos del hombre

Francesa estaba encaminada a lograr ese objetivo definitivamente, dejando atrás las viejas instituciones sociales que generaban desigualdad y sufrimiento en el pueblo. De tal manera, aplomado sobre la defensa de la constitución y la crítica a la nobleza, proclama en su texto:

En la Constitución francesa se dice No habrá títulos, y en consecuencia se elimina toda esa clase de generación equívoca que en unos países se llama aristocracia y en otros nobleza, y se asciende al par a la condición de HOMBRE [...] Si todo un país está dispuesto a despreciarlos, desaparece todo su valor y nadie quiere tenerlos. La opinión común es la única que los convierte en algo, o en nada, o en menos que nada [...] Los patriotas de Francia han descubierto a tiempo que el rango y la dignidad en la sociedad deben ocupar un nuevo terreno. El antiguo se ha hundido. Ahora deben ocupar el terreno firme del carácter, en lugar del quimérico de los títulos, y han llevado sus títulos al altar y los han quemado en sacrificio a la Razón (Paine, 2008, pp. 113-115).

Lo anterior resume su intención de decirle al pueblo que el triunfo de la era de la razón se vería materializada con la abolición de los estamentos. La victoria sobre la aristocracia o nobleza, fundada en los gobiernos de conquista y perpetrada por el derecho de primogenitura, constituiría la reivindicación de los derechos que por naturaleza son del hombre.

En síntesis, existe un uso variado del concepto de dignidad en la obra de Thomas Paine llamada Derechos del hombre, unas veces como carácter o singularidad y otras como derecho. No obstante, esto no es óbice para aparejarlo con el contemporáneo significado de dignidad humana, máxime cuando, como se dijo en párrafos anteriores, está íntimamente ligado a la naturaleza propia del hombre.

Habiendo identificado la noción de dignidad que proponen, por un lado, Edmund Burke, en su defensa historicista de la tradición y, por el otro, Thomas Paine, en favor del individualismo del yo racional, es tiempo de analizar su contenido con el fin de confrontar ambas corrientes del pensamiento político en torno al origen de las libertades.

\section{Burke us Paine: un debate también por la dignidad humana}

Hasta aquí, el lector ha encontrado dos propuestas conceptuales en torno a la dignidad, las cuales nacen del seno de una misma ideología política, o sea, el liberalismo, pero que se diferencian en el sentido que cada una de ellas le otorga a la noción, basándose, claro está, en una perspectiva iusnaturalista. Razón más que suficiente para confrontarlas en lo sucesivo de este capítulo, usando como base la clasificación que nos propone Fioravanti en relación con los modelos en los que se fundan las libertades como derechos ${ }^{14}$.

\footnotetext{
${ }^{14}$ Es celebre su frase: "La libertad, en sí, es algo que ocupa al filósofo mientras que las libertades, como derechos, son tema del jurista" (Fioravanti, 1998, p. 23).
} 
Según el historiador italiano, hay tres formas de fundamentar las libertades en el plano teórico-doctrinal, a saber, la historicista, la individualista y la estatalista (Fioravanti, 1998, p. 25). En el caso de los autores estudiados, puede afirmarse que su forma de concebir la dignidad se deriva de su correspondencia a una de estas líneas de pensamiento. Así pues, los postulados de Edmund Burke pueden ser encuadrados en la corriente historicista, en razón a que, como afirma Fioravanti:

Pensar históricamente las libertades significa situarlas en la historia y de este modo sustraerlas lo más posible a las intromisiones arbitrarias de los poderes constituidos. En este sentido, la aproximación historicista tiende inevitablemente a privilegiar las libertades civiles, las negativas, las libertades que se traducen en capacidad de obrar, en ausencia de impedimentos o de obligaciones, dentro de una esfera claramente delimitada y autónoma, sobre todo en relación con el poder político. Se piensa aquí, sobre todo, en la libertad personal y en la propiedad privada, con sus correspondientes poderes de disposición por parte del propietario (1998, p. 26).

Por su parte, Botero define esta línea del siguiente modo: "El historicismo, grosso modo, fue el modelo predominante en el Antiguo Régimen y no puede entenderse por fuera del iusnaturalismo (especialmente escolástico) y del ius commune, aunque este modelo logró sobrevivir, mutatis mutandis, a los tiempos modernos en el sistema jurídico anglo-sajón" (2015, p. 19).

Y es que, el país donde más fuerte está arraigado el modelo historicista de libertades civiles es Inglaterra. De ahí, la popularidad del binomio Liberty and property, defendido, entre otros, por Edmund Burke. Siendo así, se hace inevitable poner de presente que, en este modelo, aquellos derechos adquiridos, por el uso y el tiempo, se hacen indisponibles a la voluntad contingente de los que ostentan el poder político (Fioravanti, 1998, p. 26).

Según Fioravanti (1998), el modelo historicista destaca los tiempos históricos largos, mantiene la relación abierta y problemática entre la Edad Media y la Edad Moderna, con lo cual, no agota el tiempo de sus libertades en la edad donde se sitúa la discusión. Es más, se presenta con fascinación la Edad Media porque no se haya presente un sujeto político que crecientemente se hace titular monopolista de las funciones de imperium ${ }^{15}$ y de la capacidad normativa. El mismo que, con cierta autoridad y de manera quizá revolucionaria, pretende definir las libertades, tutelándolas con instrumentos normativos diversos, es decir, un sujeto moderno. Por esta razón, es en esta época donde tiene su origen la tradición europea de la necesaria limitación del poder político de imperium (26-27).

\footnotetext{
${ }^{15}$ El cual debe ser entendido como el "poder de imponerse en las controversias como tercero neutral con autoridad para hacer cumplir la sentencia, como poder de imponer tributos de distinto género y naturaleza, y finalmente como poder de pedir el sacrificio de la vida con la llamada a las armas" (Fioravanti, 1998, p. 27).
} 

sobre la revolución en Francia y Derechos del hombre

En la Edad Media no hay un poder político rígidamente institucionalizado, por ende, el imperium está fraccionado y dividido en un gran número de sujetos a lo largo de la escala jerárquica, ligados por una relación de fidelidad y protección. Así pues, el historicismo resalta la dimensión contractual de reciprocidad que cubre esta relación. Lo cual, según esta línea de pensamiento, no significa ausencia de derecho (28).

El fundamento de los derechos, según este modelo, se halla en la interpretación (y actualización) judicial de costumbres y textos antiguos que son considerados hitos en la historia jurídica, razón por la cual se le llama constitución histórica (Botero, 2015, p. 19). Igualmente, es notoria la permanencia de un modo típicamente medieval de organizar las relaciones políticas basado en contratos de dominación, los cuales sirven para reforzar las respectivas esferas de dominio: la del señor y la de los estamentos. Según Botero (2015), los pactos de subordinación del Medioevo no son constituciones sino ius involuntarium por varios motivos:

i) no había un "pueblo" o "nación" soberanos que se manifestaran como voluntad constituyente necesarios para hablar de constitución; ii) no había intención alguna de determinar la "ley del territorio" en tanto la idea de homogenizar el derecho en cuanto las personas y el espacio, chocaba con el pluralismo jurídico estamental dominante; iii) no había voluntad de establecer, fruto del pacto, un sujeto político nuevo que regulase el territorio de manera homogénea y que pudiera emitir normas impersonales y abstractas (igualdad formal) a los súbditos (21).

Lo que llega a ser claro es que Inglaterra, como país clave para la historia del constitucionalismo, "funda en buena parte la doctrina de su identidad históricopolítica sobre la imagen de la comunidad entre libertades medievales y modernas" (Fioravanti, 1998, p. 31). Por lo cual, su transición fue gradual y relativamente indolora en cuanto a estas últimas.

En lo que se refiere a las libertades positivas y negativas, "en el modelo historicista inglés, las libertades positivas son accesorias a las negativas, esto es, que las libertades políticas se entienden como consecuencia de la garantía a las libertades civiles, lo que va, además, de la mano de una visión corporativista de los derechos en el Medioevo, que suponía la existencia de un orden natural de las cosas" (Botero, 2015, p. 21).

Los defensores del modelo inglés destacan que, a través de la jurisprudencia, se soluciona la paradoja que se presenta entre la prohibición de cambiar el orden natural de las cosas y los cambios jurídico-políticos causados por los pactos de subordinación previos (Fioravanti, 1998, p. 34). La presencia de un elemento dinámico como la jurisprudencia es el factor de la disparidad, porque son los jueces, no los legisladores ni los príncipes, los que construyen el Common Law. La 
jurisprudencia es la que permite el cambio gradual de las libertades medievales hasta las modernas, blindando los derechos de las voluntades políticas de quienes ostenten el poder. Así, el modelo inglés, como modelo historicista, logra zafarse lentamente de la imagen medieval y el orden inmutable de las cosas, siendo dinámico gracias a los jueces.

Aunado a esto, la figura de Locke, tomada en su favor por cada una de las corrientes propuestas por el italiano, es reinterpretada en favor del historicismo bajo el entendido de que defendió la legalidad histórica violentada por los deseos monárquicos de su época, en cabeza de Carlos I y Jacobo II, en contra del Parlamento (Botero, 2015, p. 22). Y es que, en Inglaterra, la fórmula del King in Parliament que se traduce en la composición equilibrada de los tres poderes políticos del Parlamento (Monarquía, Nobleza o Lords y los Comunes) evita un modelo de gobierno despótico, de por sí lo hace moderado, al impedir que ninguna fuerza política sea dueña de la caracterización del modelo político.

Tal como se evidenció en los postulados burkeanos, la ausencia más palmaria es la de retornar a un estado de naturaleza, entendido radicalmente, donde los individuos puedan proyectar de nuevo un modelo político basado en un acuerdo de voluntades. Esto "repugna" al constitucionalismo inglés, ya que desconfía de una concepción radical del poder constituyente (Fioravanti, 1998, p. 34).

Por ende, aunque en Locke se encuentra el derecho de resistencia del pueblo en el caso de la tiranía y la disolución del gobierno; debe ser entendido como una restauración de la legalidad violada y no como herramienta para proyectar un nuevo orden político. Es más, ese pueblo que se revela es una fuerza de la historia que reconduce al gobernante a la órbita necesaria del gobierno moderado y, sobre todo, equilibrado (Fioravanti, 1998).

Este discurso iusnaturalista sobre los derechos y las libertades es el que representa claramente el pensamiento de Burke en su libro Reflexiones sobre la Revolución en Francia ${ }^{16}$. De ahí que, la dignidad, por tener un sentido sociopolítico y legal, pueda ser definida como un valor social e institucional derivado del rango u honor que se ostente en la sociedad.

\footnotetext{
${ }^{16}$ Válido sea aclarar que Burke, tal cual lo afirma Suñé (1987), rechaza el derecho natural, típica del credo radical e ilustrado. Empero, esto no significa que no apoye su teoría en una concepción del derecho natural menos especulativa. En su obra, el pensador irlandés opta por la corriente clásica, la cual "[...] estaba en íntima conexión con la religión cristiana, creencia que formaba parte de la conciencia común de Europa, y que, pese a estar dividida en varias iglesias, coincidían todas ellas en los puntos fundamentales del dogma (que no debe ser asimilado a «especulación») en el que Burke asentaba su teoría iusnaturalista. La referencia a un Dios que es Ser Supremo, Creador y Director del Universo, Autor de la naturaleza humana y Legislador de un código moral del que participan todas las religiones cristianas, era en la época, un dato" (p. 262).
} 

sobre la revolución en Francia y Derechos del hombre

Ahora bien, el discurso de Thomas Paine está enmarcado en el individualismo. Esta corriente se junta con el modelo historicista en la relación existente con el pasado medieval, pero para diferenciarse. Buscó una fractura de época entre la Edad Media (Antiguo Régimen y beneficios estamentales que otorgaban dignidad) y la Edad Moderna (al principio de igualdad formal y sometimiento a una sola ley) (Fioravanti, 1998, p. 35). Pero no por ello, como indica Botero:

(...) se pretendió una ruptura con el derecho natural. El iusnaturalismo se transformó para servir de soporte ideológico tanto al historicismo como al individualismo, de manera tal que Dios en la historia para el primero, y la razón que descubre el estado de naturaleza para el segundo, fueron los soportes de ambos modelos (2015, p. 24).

Para Fioravanti, la corriente individualista se desarrolla a través de dos líneas. La primera es una antítesis entre orden estamental y orden individual del derecho, es decir, la lucha del derecho moderno se da con parámetros individuales y antiestamentales, evidenciados perfectamente en la Revolución Francesa, cuya base se da en el iusnaturalismo ilustrado que pensó en un estado de naturaleza y prescindió de las raíces medievales (a diferencia del iusnaturalismo racionalista de Locke), proyectándose vigorosamente hacia el futuro en las declaraciones revolucionarias de derechos.

En la aproximación individualista a la problemática de las libertades no ienteresan las circunstancias de la privilegiada Edad Moderna (Estado absoluto y el legislador revolucionario). Como se pudo observar en la propuesta de Paine, la labor de las constituciones modernas es "garantizar los derechos y libertades frente al ejercicio arbitrario del poder público estatal" (Fioravanti, 1998, p. 36). Así pues, excluyendo la pertenencia estamental del sujeto en la sociedad, el individuo en cuanto tal se vuelve titular de derechos. Por ende, "el primer y más elemental derecho del individuo es poder rechazar toda autoridad distinta a la ley del Estado, ahora único titular monopolista del imperium y de la capacidad normativa y de coacción" (37).

Para los individualistas, Inglaterra no ha tenido una verdadera experiencia de Estado absoluto y menos aún una revolución con sus correspondientes declaraciones de derechos, debido a que sencillamente no ha tenido la fuerza para imponer la nueva dimensión individualista moderna al viejo orden feudal y estamental (Fioravanti, 1998). Por consiguiente, el lugar que en el historicismo ocupa Inglaterra, lo ocupa Francia en el individualismo.

En este punto, es necesario resaltar que el pensamiento de Paine también tiene rasgos de la otra línea de reflexión del individualismo, a saber, la contractualista, según la cual, la asociación política existe porque los individuos la han querido y 
construido (no por el papel restaurador de la historia) (Fioravanti, 1998, p. 38). Se inicia en Hobbes por ser quien establece la naturaleza artificial del poder político; esto es, dependiente de la voluntad de los ciudadanos. De igual manera, debe ser abatido el antiguo orden de las cosas que le asigna a cada uno los derechos y los deberes (Fioravanti, 1998), para construir ex novo un nuevo orden político con base en el consenso entre los ciudadanos.

El contractualismo, tal como el individualismo en general, tiene un lado estatalista porque aprecian la concentración de imperium propia del Estado moderno para abolir el viejo orden estamental (39). Los individualistas acuden a la soberanía estatal para destruir los privilegios y el orden estamental o como instrumento para garantizar los derechos y las libertades ${ }^{17}$.

Es claro, pues, que el esquema de pensamiento hallado en Derechos del Hombre de Thomas Paine tiene muchos matices individualistas, por consiguiente, anti-historicistas. De esta manera se puede comprender que la dignidad, en tanto derecho natural, sea de la naturaleza propia del hombre y no se logre una vez este ingresa a la sociedad. El hombre es digno por el solo hecho de existir y no por el rango u honor que ocupa en la organización política.

Antes de continuar, es necesario dejar claro al lector que ambos autores, tanto Burke como Paine, además de sus posturas contrarias, tienen cercanías con el modelo estatalista, aun cuando la base de sus postulados esté en el historicismo y el individualismo respectivamente. Por un lado, para los individualistas, como

\footnotetext{
17 Pero con esto, según Fioravanti, no se está cayendo en el riguroso estatalismo: (i) La presunción de libertad contenida en el artículo 5 de la D.D.H.C. de 1789, es decir, solo la ley puede limitar los derechos de los ciudadanos. Por ende, los jueces y administradores en el nuevo Estado de Derecho deben basarse solo en la ley general y abstracta. Es decir, las libertades, y no el poder público de coacción, son lo primero, el valor primariamente constitutivo. En el riguroso individualismo se desconfía de doctrinas estatalistas del bien común o interés general, etc, que asignan un lugar a cada uno para la empresa colectiva. Cada uno vale como individuo mas no como ciudadano más o menos fiel, solidario, movilizado, entre otras, en una empresa pública. Realmente la única justificante a limitar los derechos y libertades es la garantía de éstos en los demás. En el modelo individualista se presume la existencia de la sociedad civil de los individuos anterior al Estado (diferente al estatalista). Esa sociedad necesita del Estado para garantizar la tutela más no para fundar o crear. Los derechos y libertades no son creados por el Estado, ya existen antes de este. (ii) Se halla en la imagen del poder constituyente que reposa en los individuos y que les permite decidir el rumbo de la asociación política, del Estado. Este poder es el padre de las libertades "positivas" porque permite decidir un cierto y determinado orden político. Existen incompatibilidades claras con el historicismo, pero también con el estatalismo, porque para éste, antes del Estado no existe ningún sujeto políticamente significativo que, por ende, no puede decidir nada. Así pues, solo desde el contractualismo se puede hablar de un poder constituyente autónomo que precede poderes estatales. En otras palabras, antes de someterse a una autoridad común, existe el pactum societatis, que es la sociedad civil de los individuos o sujetos políticamente activos capaza de decidir -como pueblo o nación- el tipo de Estado. Aun así, esto no basta para el modelo, debe poder traducirse en una constitución, es decir, los individuos confían la protección de sus derechos preestatales a la constitución, como precedente a los poderes constituidos, por lo cual el imperium que se delega a éstos (poderes constituidos) se limita en garantía de la constitución (Fioravanti, 1998, pp. 41-42).
} 

sobre la revolución en Francia y Derechos del hombre

es el caso del estadounidense, es necesario acudir a la soberanía estatal para destruir los privilegios y el orden estamental o como instrumento para garantizar los derechos y las libertades. Mientras, por otro lado, en el estadista whig, como representante del historicismo, la existencia del Estado (organización política) no se deriva de la utilidad al ser un instrumento de tutela, es condición necesaria para que las libertades además de los derechos nazcan y sean tenidos como propios en cada uno de los individuos.

Una vez dilucidadas las raíces iusnaturalistas de cada noción de dignidad, es evidente que dentro del debate Burke vs Paine no se encuentra ningún significante del concepto dignidad humana, es decir, para ese entonces no había un desarrollo explícito del concepto como actualmente se conoce. No obstante, sí se hallan las bases para la construcción del significado que tiene dicha noción en el discurso de los derechos humanos.

Así pues, en la propuesta política de Edmund Burke el sentido que tiene la dignidad está asociado a lo que los romanos clásicos denominaban dignitas, es decir, un estatus dentro de la sociedad. Según McCrudden, corresponde a un factor externo al mismo hombre y depende indefectiblemente al cargo o rango que ocupe en las instituciones de la Ciudad, al punto que no está restringido al ser humano, sino que alcanza a las instituciones que hacen parte de la organización política, como, por ejemplo, la Corona y la Nobleza (McCrudden, 2008, pp. 656657).

Es por esto que en el estadista whig el concepto de dignidad corresponde a un valor social e institucional dentro del Estado. Esa orientación socio-política y legal de la noción permite hablar de dignidades en la sociedad, ninguna de ellas ligada al hombre como tal. Empero, esta perspectiva sobre la dignidad fue rebatida con la propuesta de Paine, tal cual lo indica McCrudden:

Political philosophy from a somewhat different tradition, however, contributed to the popularization of dignity, as it became closely connected with the growth of republicanism. In the French Revolution of the 18th century, 'dignities' (in the sense of aristocratic privileges) were extended to every citizen by the Declaration of the Rights of Man and of the Citizen. Thomas Paine, writing in 1791 in reply to Burke's attack on the French Revolution, partly bases his political theory on "the natural dignity of man" (2008, p. 660).

Con este cambio de panorama propuesto por Thomas Paine, la dignidad pasó a ser un derecho natural del hombre antes de entrar en la sociedad y que se mantiene incólume en ella. Siendo así, aunque la dignidad también estuvo asociada al carácter o la singularidad en la obra del estadounidense, la acepción más significativa fue haberla propuesto como un derecho del hombre por el solo 
hecho de existir. Con lo cual, la dignidad humana del discurso de los derechos humanos encuentra una de sus raíces en este importante debate del siglo XVIII.

\section{Conclusiones}

Habiendo estudiado cada una de las obras que hicieron parte del debate acaecido a finales del siglo XVIII y antes de abordar el objetivo propuesto en esta investigación, sea útil resaltar algunas conclusiones generales que se pueden extraer de los apartados anteriores.

La primera, ambas posturas liberales se enmarcan dentro del iusnaturalismo en cuanto forma de fundamentar los derechos y las libertades. Como se pudo observar, por ejemplo, en lo que se refiere a la libertad absoluta, ni Edmund Burke ni mucho menos Thomas Paine niegan su existencia previa a la constitución de la sociedad. La diferencia radica en que, mientras para aquél la libertad como derecho solo es posible dentro de la organización política, por lo que se requiere que sea viril, moral y ordenada, es decir, civil; para éste, el estadounidense, el hombre solo intercambia su derecho a la libertad absoluta del estado de naturaleza para entrar en la sociedad, que no le concede nada, sin renunciar por ese hecho a su goce.

La segunda, las dos propuestas reconocen la existencia de un contrato social previo a la sociedad civil. Empero, para el historicismo burkeano este contrato es más un pacto sancionado por Dios y la tradición es la que se encarga de decirle a los hombres cuáles son esos derechos de los que goza; mientras que, para el individualismo de Paine, se trata de un acuerdo de voluntades entre hombres políticamente activos con pleno goce de sus derechos y sus libertades, que decidieron conformar la sociedad para una mejor protección de los mismos.

La tercera, en ambas teorías, la libertad y sobre todo la igualdad están de la mano con la religión. No obstante, por un lado, en el estadista whig la propiedad privada afecta esta igualdad, sin hacerla por esto negativa, razón por la cual se hace necesaria la unión entre la Iglesia y el Estado para apaciguar la desigualdad social; mientras, de otro lado, para el pensador estadounidense, la igualdad formal ante la ley, por ser hijos del mismo creador, es una de las bases que sustentan la crítica a los privilegios de la nobleza.

Ahora bien, en cuanto al concepto de dignidad humana propuesto en cada una de las obras de los autores enfrentados y según el modelo o corriente de pensamiento que defendieron, se presentan las siguientes conclusiones.

En primer momento, no puede determinarse alguna relación entre el concepto dignidad humana manejado en el discurso de los derechos humanos y la dignidad 
que se establece en la propuesta historicista de Edmund Burke, toda vez que ésta tiene un sentido socio-político y legal que depende directamente del honor o rango que se ocupe dentro de la sociedad civil, no por la naturaleza propia del ser humano en cuanto tal. De ahí que, como se dijo anteriormente, la dignidad para Burke sea un valor social e institucional más que un atributo del hombre.

Como segunda conclusión, de manera opuesta a la noción del estadista whig, Thomas Paine, a través de su teoría de semblante individualista y contractualista, defiende el discurso de los derechos del hombre no como meras abstracciones metafísicas, sino como atributos propios del hombre previo a ingresar en la sociedad, al punto de establecer a la dignidad como un derecho natural del hombre en tanto hombre y no como un valor otorgado por la posición social dentro del Estado u organización política.

De esta manera, no queda duda que cuando alguien hable de la dignidad humana, tanto para atacarla por su ineficiencia en la realidad como para engrandecerla por la utilidad que presta a un discurso, sea inevitable acercarse al debate Burke versus Paine. La confrontación no solo es trascendental por el significado que dicho concepto tiene en la propuesta del estadounidense, ya que solo se estaría viendo una cara de la moneda; sino, además, porque la crítica del británico es también el fundamento de la crítica actual al discurso de los derechos humanos, un discurso plagado de abstracciones metafísicas llamadas derechos, cuyo receptáculo moral y ahistórico es la dignidad humana, la cual eleva al ser humano en lo conceptual pero en muy pocas ocasiones trasciende la formalidad del discurso. La dignidad humana es el fundamento del discurso de los derechos humanos y como tal, es a la vez el escollo más grande a su aplicabilidad. En tanto el ser humano no se sienta digno, aunque sea titular de derechos nunca los ejercerá.

\section{Referencias}

Aguirre, J. (2011). Dignidad, Derechos Humanos y la filosofía práctica de Kant. Vniversitas, (123), 45-74.

Bariffi, F. (2003). Negación de los Derechos Humanos: El pensamiento conservador de Edmund Burke. Revista Telemática de Filosofía del Derecho, (6), 265-278.

Bascuñán, A. (1971). Manual de técnica de la investigación jurídica. Santiago de Chile: Jurídica de Chile.

Berlin, I. (1983). Contra la corriente. Ensayos sobre la historia de las ideas. Ciudad de México: Fondo de Cultura Económica. 
Botero, A. (2008). La pluralidad de significados del conservatismo: ¿desde dónde hablamos? En E. Domínguez. (Comp.). Historia de las ideologías políticas (pp. 595614). Medellín: Fondo Editorial Universidad EAFIT.

Botero, A. (2015). Fioravanti visita Colombia: Sobre la aplicación de los modelos de cartas de derechos constitucionales. Revista Filosofía UIS, 14(2), 15-47.

Burke, E. (2013). Reflexiones sobre la Revolución en Francia (C. Mellizo, Trad.). Madrid: Alianza Editorial.

Burke, E. (1790). Reflections on the Revolution in France. Ontario, Canadá: McMaster University. Recuperado de https://socialsciences.mcmaster.ca/econ/ ugcm/3/l3/burke/revfrance.pdf.

Der Pfordten, D. (2009). On the Dignity of Man in Kant. The Royal Institute of Philosophy, 84. Recuperado de http://journals.cambridge.org.

Escolano, P. (2012). Presencia del pensamiento de Edmund Burke sobre el liberalismo doctrinario español, 1834-1854. APORTES, (79), 51-76.

Espejel, J. (2015). Liberalismo y conservadurismo en la formación disciplinaria de la Administración Pública. Cuadernos de Gobierno y Administración Pública, 2(2), 117-139.

Fioravanti, M. (1998). Los derechos fundamentales: apuntes de historia de las constituciones (M. Martínez, Trad.). Madrid: Trotta.

Fletcher, G.P. (1984). Human Dignity as a Constitutional Value. University of Western Ontario Law Review, 22.

García, J. (2016). La respuesta liberal de Edmund Burke a la crisis de legitimidad política del siglo XVIII (Tesis doctoral). Universidad Complutense de Madrid, Madrid, España.

García, M. (2017). Los Derechos Humanos desde la perspectiva de Thomas Paine (Tesis doctoral). Universidad de Extremadura, Badajoz, España.

Habermas, J. (2010). El concepto de dignidad humana y la utopía realista de los derechos humanos. Diánoia, $L V, 3-25$.

Herrera, J. (1989). Los Derechos Humanos desde la Escuela de Budapest. Madrid: Tecnos. 

sobre la revolución en Francia y Derechos del hombre

Kant, I. (2007). Fundamentación de la metafísica de las costumbres (M. García, Trad.). San Juan, Puerto Rico: Edición de Pedro Rosario.

Marín, M. (2007). La dignidad humana, los Derechos Humanos y los Derechos Constitucionales. Revista de Bioética y Derecho, (9), 1-8.

Marina, J. et al. (2000). La lucha por la dignidad: Teoría de la felicidad política. Barcelona: Anagrama.

McCrudden, C. (2008). Human Dignity and Judicial Interpretation of Human Rights. The European Journal of International Law, 19(4), 655-724.

Moncho, J. (2003). Sobre la dignidad humana. Ágora: papeles de filosofía, 22(1), 189-202.

Paine, T. (2008). Derechos del hombre (F. Santos, Trad.). Madrid: Alianza Editorial.

Peces-barba, G., et al. (2001). Historia de los Derechos Fundamentales, siglos XVIXX, Tomo II, Siglo XVIII. Madrid: Dykinson S.L.

Pico della Mirandola, G. (2010). Discurso sobre la dignidad del hombre (A. Ruíz, Trad.). Revista Digital Universitaria, 11(11), 1-6.

Pisarello, G. (2000). Vindicación de Thomas Paine. Revista Derecho del Estado, (8), 3-29.

Suñé, E. (1987). El iusnaturalismo político de Edmund Burke. Revista Persona y Derecho, (16), 205-351.

Waldron, J. (2009). Dignity, Rank, and Rights: The 2009 Tanner Lectures at UC Berkeley. NYU School of Law, Public Law Research Paper No. 09-50. Recuperado de http://ssrn.com/abstract=1461220. 